Archived version from NCDOCKS Institutional Repository http://libres.uncg.edu/ir/asu/

\title{
Appalachlan
}

B O O NE, NORTH CAROLINA

\section{Projected Health And Economic Impact Of Rotavirus Vaccination In GAVI-Eligible Countries: 2011-2030}

\author{
By: Richard D. Rheingans, Deborah E. Atherly, Kristen D.C. \\ Lewis, Jacqueline Tate \& Umesh D. Parashar
}

\begin{abstract}
Rotavirus is the leading cause of diarrheal disease in children under 5 years of age. It is responsible for more than 450,000 deaths each year, with more than $90 \%$ of these deaths occurring in lowresource countries eligible for support by the GAVI Alliance. Significant efforts made by the Alliance and its partners are providing countries with the opportunity to introduce rotavirus vaccines into their national immunization programs, to help prevent childhood illness and death. We projected the cost-effectiveness and health impact of rotavirus vaccines in GAVI-eligible countries, to assist decision makers in prioritizing resources to achieve the greatest health benefits for their populations. A decision-analytic model was used to project the health outcomes and direct costs of a birth cohort in the target population, with and without a rotavirus vaccine. Current data on disease burden, vaccine efficacy, immunization rates, and costs were used in the model. Vaccination in GAVI-eligible countries would prevent 2.46 million childhood deaths and 83 million disability-adjusted life years (DALYs) from 2011 to 2030, with annual reductions of 180,000 childhood deaths at peak vaccine uptake. The cost per DALY averted is $\$ 42$ for all GAVI countries combined, over the entire period. Rotavirus vaccination would be considered very cost-effective for the entire cohort of GAVI countries, and in each country individually, as cost-effectiveness ratios are less than the gross domestic product (GDP) per capita. Vaccination is most cost-effective and has the greatest impact in regions with high rotavirus mortality. Rotavirus vaccination in GAVIeligible countries is very cost-effective and is projected to substantially reduce childhood mortality in this population.
\end{abstract}

Richard D. Rheingans, Deborah E. Atherly, Kristen D.C. Lewis, Jacqueline Tate \& Umesh D. Parashar (2012) "Projected Health And Economic Impact Of Rotavirus Vaccination In GAVI-Eligible Countries: 2011-2030" Vaccine 30 pp.A7-A14 Version of Record Available From www.sciencedirect.com 


\section{Introduction}

Diarrhea is the second-leading cause of childhood mortality worldwide, and is responsible for approximately 1.34 million deaths each year in children under 5 years of age [1]. Rotavirus is the primary cause of diarrheal disease in this population, accounting for $30-40 \%$ of diarrheal deaths [2]. Although the illness affects children in every country, over $90 \%$ of the deaths occur in the developing world. The introduction of effective rotavirus vaccines creates the possibility of significantly reducing diarrheal mortality and hospitalizations. Growing evidence from middle and

upper income countries where rotavirus vaccination has been introduced, suggests that the vaccine is associated with reduced hospitalizations and even death among children less than 5 years of age. According to recent reports from Europe, Australia and the United States, reductions of $70-95 \%$ of hospitalizations for rotavirus-specific diarrhea and $35-48 \%$ for all-cause diarrhea have occurred after the vaccine was introduced into routine immunization programs [3-8]. These reductions in diarrheal hospitalizations have also been observed in lower-middle income countries in Latin America $[9,10]$. For the first time, real reductions in diarrheal deaths have also been recorded. In Mexico, researchers observed a $35 \%$ reduction in childhood diarrheal deaths after vaccine introduction, and in Brazil similar trends were seen [11-13].

In low-income countries that bear the vast majority of rotavirus mortality, there is less direct evidence of the effectiveness of 
vaccination at scale, in part because many of these countries are only now making decisions regarding national universal vaccination programs. Nicaragua introduced the vaccine into the routine immunization schedule in 2006 - the first GAVI-eligible country to do so. A $46 \%$ reduction against all rotavirus hospitalizations was noted, as well as a $58 \%$ reduction in the number of cases of severe rotavirus disease requiring intravenous (IV) fluids [14].

To make the decision to introduce new and relatively expensive vaccines, policy makers will benefit from reliable estimates of the costs and outcomes that might be attained through routine immunization. The best available estimates are typically based on a combination of regularly updated information on epidemiological burden, vaccine efficacy, immunization delivery, effectiveness, vaccine demand, price, and economic burden. This includes a growing number of national level studies [15-18] as well as global analyses $[19,20]$.

Improved estimates are essential for deciding whether to introduce rotavirus vaccination but also how to do so. All such ex ante analyses have uncertainties associated with them, which can be reduced as new information becomes available. Since the publication of our earlier analysis of expected impacts in GAVI-eligible countries, additional data have emerged on the vaccine efficacy in Africa and Asia [21-23], immunization delivery [24], epidemiological burden of disease [1,2], and vaccine market dynamics such as pricing and demand. Much of this new information will have a substantial influence on the cost-effectiveness and impact of rotavirus vaccines, thus highlighting the importance of an updated analysis.

\section{Methods}

\subsection{Model}

We used an Excel-based model to estimate the economic and health impact of rotavirus vaccination in GAVI-eligible countries from 2011 to 2030 [25]. Principal model inputs and their values are listed in Table 1. Annual birth cohorts were followed for a five-year period and the health outcomes and associated healthcare costs of rotavirus both with and without vaccination, were estimated for this population. GAVI-eligible countries were modeled individually and results were grouped by World Health Organization (WHO) region (see Table 2 ).

We conducted the analysis from a healthcare system perspective, focusing on costs and benefits to donors and governments. We included direct medical costs from outpatient visits and hospitalizations including the cost of diagnostic tests, medication, supplies, facilities, and personnel, as well as the cost of vaccination. Costs of informal medical treatment, as well as indirect medical and non-medical costs are not included in the model.

We estimated health burden in terms of disability-adjusted life years (DALYs) and deaths. DALYs quantify the years of life lost due to premature death and the years lived with disability [26]. We calculated DALYs due to rotavirus mortality based on the standardized life expectancy at age one [27]. DALYs from rotavirus cases resulting in outpatient or hospital visits were calculated based on default disability weights [26], an estimated illness duration of six days, and were age-weighted $[28,29]$.

Estimates of DALYs averted by universal rotavirus vaccination were used to calculate the incremental cost-effectiveness ratio (US\$/DALY averted). Estimates are expressed in 2010 US dollars, and all future costs and DALYs were discounted at a rate of $3 \%$ annually.

\subsection{Healthcare costs of rotavirus}

Country-specific estimates of hospital and outpatient costs were derived from WHO-CHOICE data [30], which standardizes costs for healthcare visits according to the geographical region and mortality stratum. We multiplied the per diem costs with an average length of hospital stay of four days [19] and diagnostic and medication costs were estimated as a proportion of the per visit and per diem costs [31,32]. Cost estimates were converted from Year 2005 international dollars to 2010 US dollars using the Consumer Price Index [33] and official exchange rates [34].

Table 1

Model parameters: values for base case scenario and ranges.

\begin{tabular}{|c|c|c|c|}
\hline Parameter & Base-case value & Range & Source \\
\hline \multicolumn{4}{|l|}{ Health } \\
\hline 5-year risk of rotavirus mortality & Country-specific & $\pm 25 \%$ & {$[55]$} \\
\hline 5-year risk of rotavirus hospitalization & 0.016 & $0.012-0.02$ & [37] \\
\hline 5-year risk of rotavirus outpatient visit & 0.202 & $0.152-0.252$ & [37] \\
\hline Average hospital length of stay & 4 days & $3-5$ & [19] \\
\hline $\begin{array}{l}\text { Years of life lost (YLL) per death-discounted, } \\
\text { age weighted }\end{array}$ & 34 & $\mathrm{NA}$ & [56] \\
\hline $\begin{array}{l}\text { Years of life lived with disability (YLD) per } \\
\text { event-discounted, age-weighted }\end{array}$ & 0.00037 & NA & [56] \\
\hline \multicolumn{4}{|l|}{ Vaccine efficacy } \\
\hline Against severe rotavirus gastroenteritis & $57 \%$ (high) & $41-69 \%$ (high) & {$[21-23,57-59]$} \\
\hline resulting in hospitalization or death (by & $72 \%$ (mid) & $55-85 \%$ (mid) & \\
\hline childhood mortality strata) & $85 \%$ (low) & $70-94 \%$ (low) & \\
\hline Against all-severity rotavirus gastroenteritis & $47 \%$ (high) & $32-60 \%$ (high) & {$[21-23,57-59]$} \\
\hline (by childhood mortality strata) & $70 \%$ (mid) & $56-80 \%$ (mid) & \\
\hline & $78 \%($ low) & $58-89 \%$ (low) & \\
\hline $\begin{array}{l}\text { Against severe all-cause gastroenteritis (high } \\
\text { childhood mortality setting) }\end{array}$ & $24.8 \%$ & $12.6-35.3 \%$ & [21-23] \\
\hline Efficacy of one dose & $\begin{array}{l}50 \% \text { of full course } \\
\text { efficacy }\end{array}$ & & Assumption \\
\hline Relative coverage & $90 \%$ & $60-100 \%$ & Assumption \\
\hline \multicolumn{4}{|l|}{ Costs } \\
\hline Hospitalization unit cost & $\$ 17-232$ & $\pm 25 \%$ & WHO-CHOICE website \\
\hline Outpatient unit cost & $\$ 1-13$ & $\pm 25 \%$ & WHO-CHOICE website \\
\hline Vaccine program cost per dose & $\$ 0.25-1.25$ & $\pm 25 \%$ & [35] \\
\hline
\end{tabular}


Table 2

GAVI-eligible countries by WHO region.

\begin{tabular}{|c|c|c|c|c|c|c|}
\hline $\begin{array}{l}\text { AMR-Region of } \\
\text { the Americas }\end{array}$ & $\begin{array}{l}\text { EUR-European } \\
\text { Region }\end{array}$ & AFR-African Region & & $\begin{array}{l}\text { EMR-Eastern } \\
\text { Mediterranean Region }\end{array}$ & $\begin{array}{l}\text { SEAR-Southeast } \\
\text { Asian Region }\end{array}$ & $\begin{array}{l}\text { WPR-Western } \\
\text { Pacific Region }\end{array}$ \\
\hline Bolivia & Armenia & Angola & Lesotho & Afghanistan & Bangladesh & Cambodia \\
\hline Cuba & Azerbaijan & Benin & Liberia & Djibouti & Bhutan & Kiribati \\
\hline Guyana & Georgia & Burkina Faso & Madagascar & Pakistan & DPR Korea & Lao PDR \\
\hline Haiti & Kyrgyzstan & Burundi & Malawi & Somalia & India & Mongolia \\
\hline Honduras & Moldova & Cameroon & Mali & Sudan & Indonesia & $\begin{array}{l}\text { Papua New } \\
\text { Guinea }\end{array}$ \\
\hline \multirow[t]{13}{*}{ Nicaragua } & Tajikistan & Central African Republic & Mauritania & Yemen & Myanmar & $\begin{array}{l}\text { Solomon } \\
\text { Islands }\end{array}$ \\
\hline & Ukraine & Chad & Mozambique & & Nepal & Vietnam \\
\hline & Uzbekistan & Comoros & Niger & & Sri Lanka & \\
\hline & & Congo & Nigeria & & Timor-Leste & \\
\hline & & Congo DR & Rwanda & & & \\
\hline & & Côte d'Ivoire & São Tomé \& Principe & & & \\
\hline & & Eritrea & Senegal & & & \\
\hline & & Ethiopia & Sierra Leone & & & \\
\hline & & Gambia & Tanzania & & & \\
\hline & & The Ghana & Togo & & & \\
\hline & & Guinea & Uganda & & & \\
\hline & & Guinea-Bissau & Zambia & & & \\
\hline & & Kenya & Zimbabwe & & & \\
\hline
\end{tabular}

\subsection{Vaccination program costs}

Vaccination program costs include those costs associated with storing, delivering and administering the vaccine once it arrives in the country. The vaccine program costs were estimated using the WHO Global Immunization Vision and Strategy (GIVS) costing tool [35]. A program cost per dose was estimated for each of the countries, and a regional, weighted average was calculated and used in the analysis.

\subsection{Health care utilization and mortality associated with rotavirus}

We used updated country estimates of childhood deaths due to diarrhea and rotavirus-specific illness, to revise the baseline disease burden figures for our analysis $[1,36]$. We estimated rotavirusassociated outpatient visits and hospitalizations by multiplying the total diarrhea-related outpatient visits and hospitalizations by the estimated proportion attributable to rotavirus [37]. Rotavirus medical visits and deaths were distributed into the following age categories: 0-2 months, 3-5 months, 6-8 months, 9-11 months, 12-23 months, 24-35 months, 36-47 months, and 48-59 months [19].

\subsection{Vaccine efficacy}

Recent clinical trials of rotavirus vaccine in sub-Saharan Africa and Southeast Asia found lower levels of vaccine efficacy than observed in trials in Latin America that were used in the original model [21-23]. As noted by the WHO Strategic Advisory Group of Experts (SAGE), this finding is not unexpected [38] and is consistent with results from studies of other live, oral vaccines such as polio, typhoid and cholera that suggest lower efficacy or immunogenicity in developing country populations compared to industrialized countries [39-41].

Efficacy estimates against severe rotavirus diarrhea, any rotavirus diarrhea, and all-cause severe gastroenteritis for countries in the African and Asian regions were calculated and applied by child mortality strata (see Table 1 ). Pooled random effects mean estimates from the trials conducted in the high mortality countries of Ghana, Kenya, Bangladesh, South Africa, Malawi and Mali were applied to countries with under-5 mortality rates $>30 / 1000$. Estimates from the study in Vietnam were applied to countries with child mortality rates $\leq 30 / 1000$. Previous estimates from trials in Latin America were still used for Latin American and Caribbean countries. Estimates of efficacy against severe rotavirus gastroenteritis are used as a proxy for efficacy against mortality and hospitalization, and efficacy against any rotavirus gastroenteritis corresponds to efficacy against outpatient visits.

\subsection{Forecasted demand and price over time}

Atherly et al. [19] demonstrated that estimates of the impact and cost-effectiveness of vaccination over time depend heavily on assumptions about which countries introduce vaccine, the timing of their introduction and how price changes over time as a result of market factors such as increased demand and the entry of new manufacturers. Many countries have expressed interest in rotavirus vaccines, leading several to apply for vaccine support from GAVI [42]. Recent estimates have projected a total of over 40 country introductions of rotavirus vaccine by 2015 ; this figure is in addition to the five countries that introduced vaccine prior to $2012[43,44]$. Thus, for this analysis we have assumed that a total of 47 countries will adopt by 2015 , based on current GAVI predictions. We estimated that 17 of the remaining 25 countries would introduce vaccine by 2020, and 8 countries after 2020. See Table 2 for the complete list of countries. Some countries may graduate from GAVI eligibility before or after they have introduced vaccine. However, estimates of benefits and costs over the entire analysis timeframe account for all expected rounds of vaccination in currently eligible countries assuming that graduating countries will be able to adopt and/or sustain their rotavirus immunization programs after graduation.

Vaccine prices were estimated from current and expected price agreements between the purchasing agents for GAVI-eligible countries (UNICEF and PAHO), and the vaccine manufacturers. The average price of rotavirus vaccine is expected to decline over the analysis timeframe. In 2011, we used an initial vaccine price of $\$ 7.50$ per dose for a 2-dose regimen based on existing multinational supplier contracts with low to middle-income countries and their agents, in Latin America [45]. Between 2012 and 2015 we used an estimated average price of $\$ 3.50$ per dose for a 2-dose regimen, based on pledges made by existing multinational suppliers [46]. Beginning in 2016, the price falls to $\$ 2.00$ and then to $\$ 1.50$ in 2018 , reflecting competition and price decline due to the projected entry of products from developing country manufacturers [47]. 


\subsection{Vaccine coverage and delivery}

We estimated vaccine coverage using UNICEF/WHO best estimates for DPT1 and DTP2 for each country. Then, updated estimates on the timing of routine vaccinations from Clark et al. were incorporated [24]. We also assumed that the coverage rate for children at the highest risk of rotavirus mortality was $90 \%$ of the vaccination rate for other children, since children who die of diarrhea may have had less access to vaccination and other health care resources [48].

\subsection{Sensitivity analyses}

One-way sensitivity analysis was conducted to assess the impact of specific variables on the number of deaths averted and costeffectiveness of vaccination. Variables included rotavirus mortality incidence, vaccine efficacy, relative coverage (the adjustment made for inequitable vaccine access in those children most likely to die), vaccination program costs, and timing of vaccine dosing.

A probabilistic uncertainty analysis was done to assess the combined effect of multiple variables on vaccination impact (deaths averted) and cost-effectiveness (\$/DALY averted) in the base-case analysis. A Monte Carlo simulation was performed using distributions for the key input variables, including rotavirus mortality, vaccine efficacy, vaccination systems costs, and relative coverage. Multiple iterations $(10,000)$ randomly drew values from the input variable distributions and generated a distribution of output values and corresponding uncertainty limits (5th and 95th percentiles of the output distributions).

\subsection{Scenario analyses}

\subsubsection{Efficacy against severe all-cause gastroenteritis}

Pooled data from the trials in Africa and Asia were used to estimate the deaths averted and cost-effectiveness of vaccine against severe, all-cause gastroenteritis. Since data from the Latin American and Caribbean (AMR) and European (EUR) regions were not available, we used the base case estimates for rota-specific efficacy and impact in these regions, to allow us to report total GAVI estimates.

\subsubsection{Indirect benefits}

For some vaccines, indirect protection through herd immunity is an important determinant of impact as it benefits populations who may not be reached with routine vaccination [49]. There is some evidence from large scale introduction studies of rotavirus vaccines that are consistent with indirect protection. For example, data from the United States, El Salvador and Australia indicate declines in rotavirus disease among older, unvaccinated children $[4,50,51]$. Currently, there is insufficient evidence to firmly establish such an effect so we have not incorporated it into our base case estimates of effectiveness. However, a scenario on indirect effects has been included as a part of our sensitivity analysis. This indirect effects scenario assumed that for each outcome, non-vaccinated children would receive a level of protection proportional to the efficacy in vaccinated children and the level of coverage. Specifically, we assumed that unvaccinated children would receive half of the level of protection as vaccinated children, times the proportion of children vaccinated. So at 50\% coverage and 60\% efficacy in vaccinated children, unvaccinated would receive $15 \%$ protection, while at $95 \%$ coverage, unvaccinated children would receive $28.5 \%$ protection. These simplified assumptions are intended to provide a preliminary estimate of the potential impact.

\subsubsection{Constant vaccine price over time}

Vaccine price is an important determinant of both costeffectiveness and affordability. The base case represents a price trajectory over time, but it is also important to understand the relative cost-effectiveness of vaccine at various set prices. We ran scenarios to determine the cost-effectiveness of vaccination at prices of $\$ 7.00, \$ 5.00, \$ 2.50$ and $\$ 1.50$ per dose, assuming those prices remain constant through 2030 .

\section{Results}

\subsection{Base case: vaccine impact}

Between 2011 and 2030, rotavirus vaccination for 72 GAVIeligible countries is projected to avert the deaths of more than 2.4 million children, and prevent more than 83 million disabilityadjusted life years (DALYs) (Table 3 ). Ranges for these figures, calculated from probabilistic sensitivity analysis are 1.8-3 million deaths and 54-95 million DALYs averted. More than 95\% of the averted burden would occur in the African (AFR), Eastern Mediterranean (EMR) and Southeast Asian (SEAR) regions combined. For every 1000 children vaccinated, 89 health care visits, $\$ 1000$ in medical expenses and 93 DALYs would be avoided. The health benefits per 1000 children vaccinated vary widely, and are highest in the GAVI-eligible countries of the Eastern Mediterranean (142 DALYs averted) and African (118 DALYs averted) regions and lowest in the Western Pacific region (13 DALYs averted). The EMR and AFR regions include several high rotavirus mortality countries, while seventy percent of the GAVI-eligible population in the WPR region

Table 3

Base-case results-impact and cost-effectiveness of the introduction of rotavirus vaccines into GAVI-eligible countries from 2011 to 2030.

\begin{tabular}{|c|c|c|c|c|c|c|c|}
\hline & \multicolumn{7}{|l|}{ WHO region } \\
\hline & AMR & EUR & AFR & EMR & SEAR & WPR & All GAVI \\
\hline Total number of deaths averted & 39,140 & 24,270 & $1,352,870$ & 549,830 & 482,300 & 10,100 & $\begin{array}{l}2,458,510 \\
(1,800,000-3,000,000)\end{array}$ \\
\hline Total DALYs averted & $1,335,000$ & 829,800 & $46,132,900$ & $18,725,200$ & $16,448,400$ & 347,400 & $\begin{array}{l}83,818,700 \\
(54,000,000-95,000,000)\end{array}$ \\
\hline \multicolumn{8}{|c|}{ Impact per 1000 children vaccinated } \\
\hline DALYs averted & $78(58-84)$ & $37 \quad(20-45)$ & $118(71-137)$ & $142(89-173)$ & $52(34-65)$ & $13 \quad(6-15)$ & $\begin{array}{l}93 \\
(56-108)\end{array}$ \\
\hline Health care visits averted & 145 & 125 & 85 & 85 & 87 & 114 & 89 \\
\hline Medical costs averted & $\$ 2260$ & $\$ 2130$ & $\$ 600$ & $\$ 960$ & $\$ 1360$ & $\$ 885$ & $\$ 1000$ \\
\hline \multicolumn{8}{|c|}{ Cost per DALY averted 2010 (US\$) } \\
\hline $\begin{array}{l}\text { Projected price trajectory } \\
\text { from } 2011 \text { to } 2030 \text { (confidence } \\
\text { range: } 5-95 \% \text { ) }\end{array}$ & $\$ 63(\$ 44-90)$ & $\$ 116(\$ 62-173)$ & $\$ 38(\$ 26-55)$ & $\$ 30(\$ 18-40)$ & $\$ 60(\$ 45-90)$ & $\$ 231(\$ 170-440)$ & $\$ 42(\$ 31-64)$ \\
\hline $\begin{array}{l}\text { Range of lowest and highest } \\
\text { GDP per capita for countries } \\
\text { included in each region [60] }\end{array}$ & $650-2600$ & $720-2800$ & $160-1200$ & $500-1300$ & $400-1800$ & $700-1300$ & $150-2800$ \\
\hline
\end{tabular}


Table 4

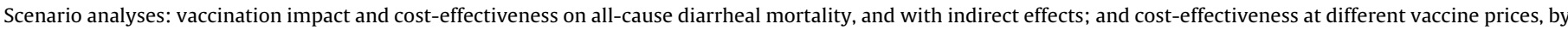
WHO region and all GAVI countries.

\begin{tabular}{|c|c|c|c|c|c|c|c|}
\hline & \multicolumn{7}{|l|}{ Region } \\
\hline & AMR & EUR & AFR & EMR & SEAR & WPR & All GAVI \\
\hline \multicolumn{8}{|l|}{ Base case scenario } \\
\hline Deaths averted & 39,140 & 24,275 & $1,352,870$ & 549,830 & 482,300 & 10,100 & $2,458,510$ \\
\hline Cost/DALY averted & $\$ 63$ & $\$ 116$ & $\$ 38$ & $\$ 30$ & $\$ 60$ & $\$ 231$ & $\$ 42$ \\
\hline \multicolumn{8}{|c|}{ Scenario 1. All-cause diarrheal mortality } \\
\hline Deaths averted & 39,140 & 24,275 & $1,786,000$ & 590,300 & 505,540 & 10,300 & $2,955,555$ \\
\hline Cost/DALY averted & $\$ 63$ & $\$ 116$ & $\$ 30$ & $\$ 30$ & $\$ 66$ & $\$ 254$ & $\$ 39$ \\
\hline \multicolumn{8}{|c|}{ Scenario 2. Indirect effects } \\
\hline Deaths averted & 47,025 & 32,090 & $1,703,880$ & 668,500 & 588,800 & 11,880 & $3,052,175$ \\
\hline Cost/DALY averted & $\$ 50$ & $\$ 78$ & $\$ 30$ & $\$ 25$ & $\$ 46$ & $\$ 190$ & $\$ 33$ \\
\hline \multicolumn{8}{|c|}{ Scenario 3. Constant vaccine price over time: cost/DALY averted } \\
\hline$\$ 7.00$ & 197 & 318 & 138 & 100 & 264 & 1152 & 176 \\
\hline$\$ 5.00$ & 137 & 226 & 100 & 71 & 185 & 815 & 125 \\
\hline$\$ 2.50$ & 61 & 111 & 53 & 36 & 87 & 394 & 62 \\
\hline$\$ 1.50$ & 31 & 65 & 34 & 22 & 48 & 225 & 37 \\
\hline
\end{tabular}

is represented by Vietnam, a country with good rotavirus surveillance data and a very low rotavirus mortality rate.

Annual deaths averted rise sharply between 2011 and 2019 as countries are introducing vaccine into their national immunization systems (Fig. 1). Once full introduction and target vaccine coverage is reached in all 72 countries, rotavirus vaccine is expected to prevent approximately 180,000 of the 429,000 estimated rotavirus deaths each year in these countries, reaching a cumulative 2.46 million deaths averted by 2030 .

\subsection{Base case: cost-effectiveness}

Under the base case scenario, the cost-effectiveness of rotavirus vaccination is $\$ 42 /$ per DALY averted. Cost-effectiveness ratios were highest in the Western Pacific region (\$231) and lowest in the Eastern Mediterranean (\$30). The World Health Report suggests that an intervention averting one DALY at a cost that is less than the GDP per capita, is very cost-effective. Those averting each DALY at a cost between one and three times the GDP per capita are cost effective [52]. Based on this threshold, rotavirus vaccination under the base-case scenario, is very cost-effective in every region. The lowest GDP per capita in each region (representing the poorest country) is higher than the $\mathrm{CE}$ ratio for that region, and is higher than the upper value of the confidence range as well, suggesting that vaccination is very cost-effective in all 72 countries. The cost-effectiveness decreases over time as the number of infants vaccinated increases (Fig. 2). The higher ratios in the first two years are primarily driven by a higher vaccine price and the presence of vaccination programs in relatively lower burden countries of Latin America. As time progresses, the price drops dramatically and higher-burden countries begin to introduce the vaccine, leading to lower, more favorable cost-effectiveness ratios.

\subsection{Scenario analysis}

Under an alternative scenario including all-cause diarrhea mortality, rotavirus vaccination is projected to avert more than 2.9 million deaths associated with all causes of diarrhea, with $60 \%$ of the impact occurring in the African region (Table 4). The costeffectiveness is $\$ 39$ per DALY averted for all regions combined, with a high of $\$ 254$ in the Western Pacific region and low of $\$ 30$ in the African and Eastern Mediterranean regions, meeting the threshold for a very-cost-effective intervention at the global and regional levels. Under a scenario that assumes indirect benefits of vaccination, rotavirus vaccine is once again, very cost-effective and could avert the deaths of an estimated 3 million children in GAVI-eligible countries.

Vaccination remains very cost-effective for all GAVI countries combined, under all price scenarios. At $\$ 7.00$ per dose, the cost per DALY averted is $\$ 176$, and at a low of $\$ 1.50$ per dose, the incremental CE ratio is $\$ 37$. Regionally, vaccination is very-cost-effective in all regions at all price levels, with the exception of the Western Pacific region, where it is between one and three times GDP at prices of $\$ 7.00$ and $\$ 5.00$ per dose.

\subsection{One-way sensitivity analysis}

Only small changes in the cost-effectiveness of vaccination occurred when values for key variables were changed (Table 5). The $\mathrm{CE}$ ratio increases to a high of $\$ 62$ when relative coverage decreases to $60 \%$ and the ratio declines to a low of $\$ 32$ when rotavirus mortality estimates are increased by $25 \%$. Variations in estimates of vaccine efficacy, baseline rotavirus mortality and relative coverage have a substantial impact on projected deaths averted, whereas changes in the timing of vaccination have a more modest effect.

Table 5

One-way sensitivity analysis showing the influence of selected variables on the costeffectiveness and impact of vaccination.

\begin{tabular}{lll}
\hline & Deaths averted & Cost/DAIY averted (US\$) \\
\hline Base case & $2,458,510$ & 42 \\
RV mortality & & \\
Base & $2,458,510$ & 42 \\
$25 \%$ & $3,073,000$ & 32 \\
$-25 \%$ & $1,844,000$ & 54 \\
Vaccine efficacy & & \\
Base & $2,458,510$ & 42 \\
High & $2,802,000$ & 36 \\
Low & $1,936,210$ & 56 \\
Relative coverage & & \\
100\% & $2,729,000$ & 37 \\
Base - 90\% & $2,458,510$ & 42 \\
60\% & $1,647,000$ & 62 \\
Timing & & \\
Base - current & $2,458,510$ & 42 \\
On-time & $2,658,000$ & 39 \\
Vaccination system cost & & \\
Base - GIVS & $2,458,510$ & 42 \\
50\% & N/A & 48 \\
-50\% & N/A & 36 \\
\hline & & \\
\hline
\end{tabular}




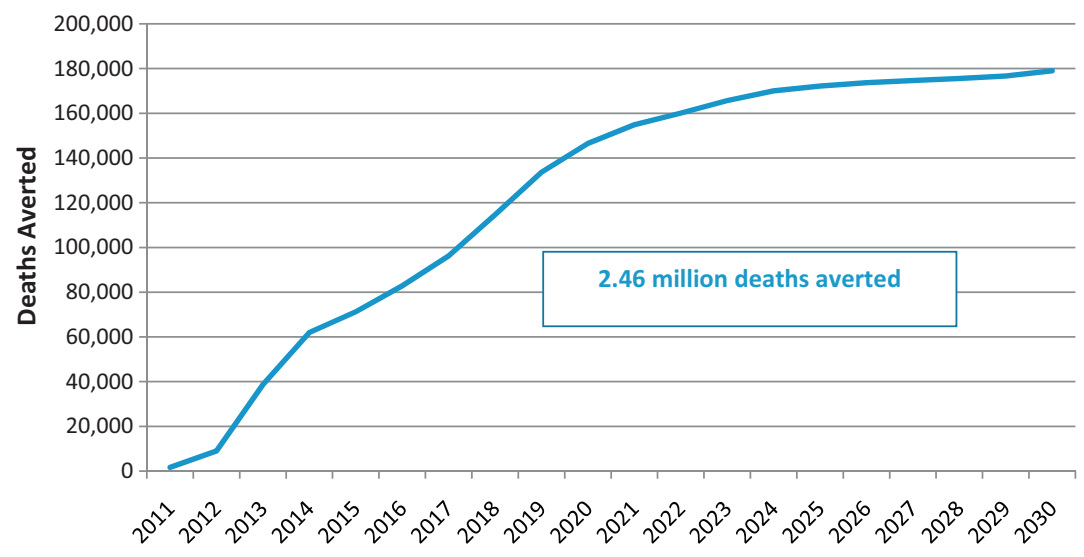

Fig. 1. Annual and cumulative deaths averted, 2011-2030.

\section{Discussion}

This analysis focuses specifically on estimating the health impact and cost-effectiveness of rotavirus vaccination in GAVIeligible countries, utilizing recent developments in the field. We have incorporated the reported vaccine efficacy data from lowresource settings in Africa and Asia, utilizing pooled estimates based on Under5 mortality strata [53]. We have used the recently updated WHO estimates for rotavirus mortality, which are slightly lower than previously reported [36]. In addition, this analysis captures evolutions in market dynamics such as the increased demand for vaccine in high-burden countries and reductions in vaccine prices. There has been a surge in country applications from GAVIeligible countries for rotavirus vaccines, and the first in Africa North Sudan - initiated rotavirus immunization in the national childhood immunization schedule in July 2011 [42].

The 72 countries included in this analysis carry nearly $95 \%$ of the burden of rotavirus mortality, accounting for approximately 429,000 annual deaths in young children under five. The introduction of rotavirus vaccines in these GAVI-eligible countries will have significant public health impact in terms of deaths and hospitalizations averted, and would be considered a very costeffective intervention. Rotavirus immunization could avert the deaths of 2.46 million children in these countries between 2011 and 2030. Cost-effectiveness improves rapidly in the early years, when vaccine price reductions are anticipated and high-mortality countries begin to introduce vaccine.

Rotavirus vaccines have demonstrated modest vaccine efficacy in resource poor settings with the highest rates of Under 5 mortality and rotavirus associated mortality [21-23]. Annual reduction of 180,000 childhood deaths could be expected in these countries, representing a $42 \%$ reduction in total rotavirus mortality. Lower vaccine efficacy in high burden countries is the primary factor limiting overall impact. However, $98 \%$ of the estimated rotavirus deaths averted among these countries occur in those with the highest rates of childhood death and lowest vaccine efficacy. For instance, the 10 countries with the highest rates of rotavirus mortality per capita $(>300 / 100,000)$ are in Africa and the Middle East. These would experience the greatest benefit from the introduction of rotavirus vaccines. So despite lower efficacy, the public health impact will be enormous in those countries with the greatest burden.

Regional variations in the cost-effectiveness and public health impact of rotavirus vaccination were observed in this analysis. These regional differences in cost-effectiveness and health outcomes are more influenced by underlying disease burden than by vaccine efficacy. For example, despite lower estimated vaccine efficacy in the African and Eastern Mediterranean populations, the vaccine has the greatest public health impact - measured by DALYs averted per 1000 children vaccinated - and is the most costeffective in these regions that carry the highest rotavirus mortality

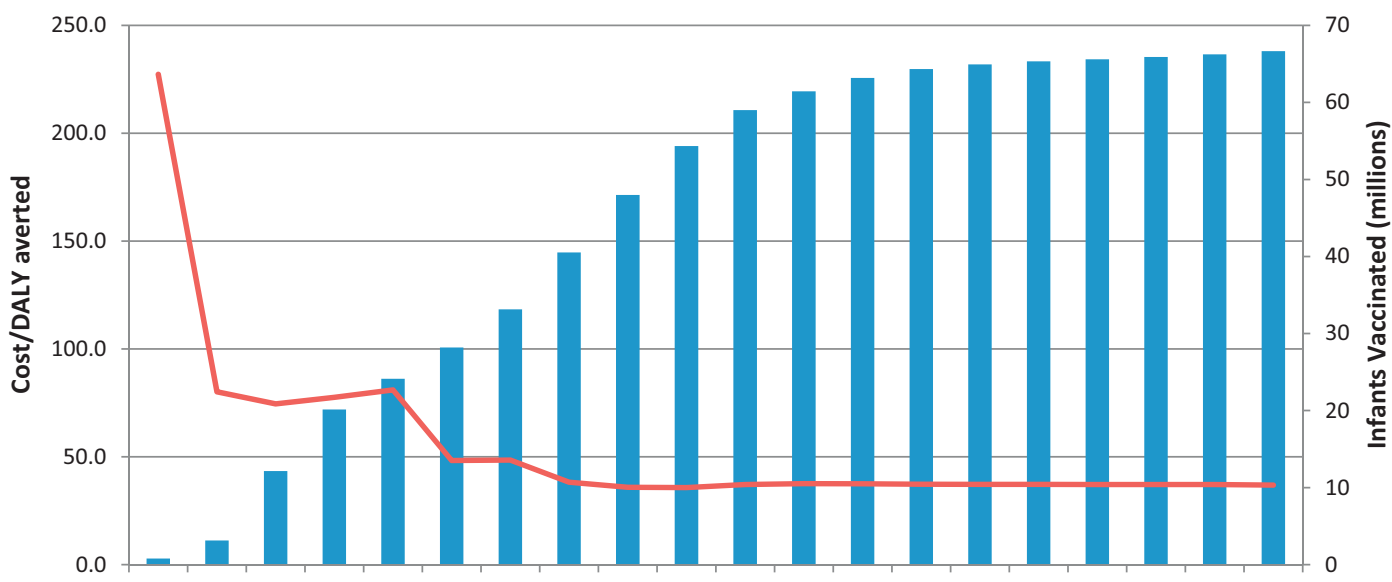

20112012201320142015201620172018201920202021202220232024202520262027202820292030

\# infants vaccinated $\quad$ cost-effectiveness ratio

Fig. 2. Annual cost-effectiveness ratio and number of infants vaccinated over time. 
rates. In contrast, countries included in the Western Pacific region have the lowest average mortality rate, and although higher vaccine efficacy estimates were applied to this population, the health impact is smaller and the cost-effectiveness ratio is higher compared to other regions.

Of global health importance is the overall impact of rotavirus vaccines on all-cause severe diarrheal morbidity and mortality. Applying the figure of $24.8 \%$ vaccine efficacy against all-cause severe gastroenteritis deaths (pooled estimate as described above), yields estimates of the impact of vaccine that are $20 \%$ higher than the base case results of 2.46 million rotavirus deaths averted. The difference may be explained, in part, by undetected rotavirus in the populations from which these all-cause diarrhea efficacy results were derived, due to late presentation in the course of the diarrheal episode and/or limited diagnostic sensitivity of the ELISA system used. The variance may also be due to an overestimate of vaccine efficacy against all-cause severe gastroenteritis in the clinical trials. For example, if all-cause efficacy was measured only through the rotavirus season and then annualized, the estimate would be falsely high.

Results from the scenario that modeled the indirect effects of vaccination suggest that the impact may be greater than estimated in the base case. The $25 \%$ increase in deaths averted is dependent upon the simplifying assumptions used in modeling this scenario. It is not surprising that impact expands, since more children are benefiting from vaccination compared to the base case. In addition to improving overall impact, indirect protection may also increase equity by providing protection to higher risk children who would not otherwise be vaccinated. However this would likely depend on proximity and other population dynamics between vaccinated and unvaccinated children, and needs to be examined in the field.

This study has some limitations. We used DPT vaccine coverage as a proxy for rotavirus vaccines; however, we did not include the potential impact on coverage by the age restrictions placed on the timing of administration of rotavirus vaccines [54]. The restrictions may decrease overall coverage, and therefore impact, compared to that achieved with DPT, but these data will only be available after countries have introduced. We did lower DPT coverage rates in our base case analysis though, to account for the assumption that there may be inequity in vaccine coverage, especially for those most likely to die from rotavirus, thus resulting in a more conservative estimate. As more data become available, these coverage assumptions will become more refined and accurate. In addition, although we have used available data and historical trends to project country introductions, it is very difficult to accurately predict adoption patterns, particularly more than a few years in the future. We have illustrated a snapshot of one potential demand scenario that attempts to capture the impact of rotavirus vaccines in all GAVIeligible countries. However, changes in the timing and inclusion of country introductions will occur as time goes on, so updated analyses will be required to reflect the impact of these changes.

This analysis strongly supports the WHO recommendation for the introduction of the live, oral rotavirus vaccines in countries with high Under5 mortality, high diarrheal incidence and limited health resources. Rotavirus immunization is very cost effective and has significant public health impact in the GAVI-eligible countries which carry the greatest burden of rotavirus morbidity and mortality. Rotavirus vaccines are utilized in several middle- and high-income countries where there has been a dramatic decline in rotavirus associated hospitalizations and savings to the medical health system. As the GAVI Alliance is bridging the funding gap for new vaccines, and many countries are applying for financial support, the major impact of rotavirus vaccines on child mortality and health in the hardest hit populations may soon be realized.

\section{Disclosures}

This study was funded by PATH's Rotavirus Vaccine Program under a grant from the GAVI Alliance.

\section{Conflict of interest}

The authors have no conflicts to declare.

\section{Disclaimer}

The findings and conclusions of this report are those of the authors and do not necessarily represent the views of the Centers for Disease Control and Prevention.

\section{References}

[1] Black RE, Cousens S, Johnson HL, Lawn JE, Rudan I, Bassani DG, et al. Global, regional, and national causes of child mortality in 2008: a systematic analysis. Lancet 2010;375(June (9730)):1969-87.

[2] Parashar UD, Burton A, Lanata C, Boschi-Pinto C, Shibuya K, Steele D, et al. Global mortality associated with rotavirus disease among children in 2004. J Infect Dis 2009;200(November (Suppl. 1)):S9-15.

[3] Boom JA, Tate JE, Sahni LC, Rench MA, Hull JJ, Gentsch JR, et al. Effectiveness of pentavalent rotavirus vaccine in a large urban population in the United States. Pediatrics 2010;125(February (2)):e199-207.

[4] Cortese MM, Tate JE, Simonsen L, Edelman L, Parashar UD. Reduction in gastroenteritis in United States children and correlation with early rotavirus vaccine uptake from National Medical Claims Databases. Pediatr Infect Dis J 2010;29(June (6)):489-94.

[5] Snelling TL, Schultz R, Graham J, Roseby R, Barnes GL, Andrews RM, et al. Rotavirus and the indigenous children of the Australian outback: monovalent vaccine effective in a high-burden setting. Clin Infect Dis 2009;49(August (3)):428-31.

[6] Paulke-Korinek M, Rendi-Wagner P, Kundi M, Kronik R, Kollaritsch H. Universal mass vaccination against rotavirus gastroenteritis: impact on hospitalization rates in Austrian children. Pediatr Infect Dis J 2010;29(April (4)):319-23.

[7] Buttery JP, Lambert SB, Grimwood K, Nissen MD, Field EJ, Macartney KK, et al Reduction in rotavirus-associated acute gastroenteritis following introduction of rotavirus vaccine into Australia's National Childhood vaccine schedule. Pediatr Infect Dis J 2011;30(January (Suppl. 1)):S25-9.

[8] Braeckman T, Van Herck K, Raes M, Vergison A, Sabbe M, Van Damme P. Rotavirus vaccines in Belgium: policy and impact. Pediatr Infect Dis J 2011;30(January (Suppl. 1)):S21-4.

[9] Quintanar-Solares M, Yen C, Richardson V, Esparza-Aguilar M, Parashar UD, Patel MM. Impact of rotavirus vaccination on diarrhea-related hospitalizations among children $<5$ years of age in Mexico. Pediatr Infect Dis J 2011;30(January (Suppl. 1)):S11-5.

[10] Yen C, Armero Guardado JA, Alberto P, Rodriguez Araujo DS, Mena C, Cuellar $\mathrm{E}$, et al. Decline in rotavirus hospitalizations and health care visits for childhood diarrhea following rotavirus vaccination in El Salvador. Pediatr Infect Dis J 2011;30(January (Suppl. 1)):S6-10.

[11] do Carmo GM, Yen C, Cortes J, Siqueira AA, de Oliveira WK, Cortez-Escalante $\mathrm{JJ}$, et al. Decline in diarrhea mortality and admissions after routine childhood rotavirus immunization in Brazil: a time-series analysis. PLoS Med 2011;8(April (4)):e1001024

[12] Richardson V, Parashar U, Patel M. Childhood diarrhea deaths after rotavirus vaccination in Mexico. N Engl J Med 2011;365(August (8)):772-3.

[13] Richardson V, Hernandez-Pichardo J, Quintanar-Solares M, Esparza-Aguilar M, Johnson B, Gomez-Altamirano CM, et al. Effect of rotavirus vaccination on death from childhood diarrhea in Mexico. N Engl J Med 2010;362(January (4)):299-305.

[14] Patel M, Pedreira C, De Oliveira LH, Tate J, Orozco M, Mercado J, et al. Association between pentavalent rotavirus vaccine and severe rotavirus diarrhea among children in Nicaragua. JAMA 2009;301(January (21)):2243-51.

[15] Tate JE, Kisakye A, Mugyenyi P, Kizza D, Odiit A, Braka F. Projected health benefits and costs of pneumococcal and rotavirus vaccination in Uganda. Vaccine 2011;29(17):3329-34.

[16] Esposito DH, Tate JE, Kang G, Parashar UD. Projected impact and costeffectiveness of a rotavirus vaccination program in India. Clin Infect Dis 2008;52(January (2)):171-7.

[17] Clark AD, Walker DG, Mosqueira NR, Penny ME, Lanata CF, Fox-Rushby $\mathrm{J}$, et al. Cost-effectiveness of rotavirus vaccination in Peru. J Infect Dis 2009;200(November (Suppl. 1)):S114-24

[18] Tate JE, Rheingans RD, O'Reilly CE, Obonyo B, Burton DC, Tornheim JA, et al. Rotavirus disease burden and impact and cost-effectiveness of a rotavirus vaccination program in Kenya. J Infect Dis 2009;200(November(Suppl. 1)):S76-84

[19] Atherly D, Dreibelbis R, Parashar UD, Levin C, Wecker J, Rheingans RD. Rotavirus vaccination: cost-effectiveness and impact on child mortality in developing countries. J Infect Dis 2009;200(November (Suppl. 1)):S28-38. 
[20] Rheingans RD, Antil L, Dreibelbis R, Podewils LJ, Bresee JS, Parashar UD. Economic costs of rotavirus gastroenteritis and cost-effectiveness of vaccination in developing countries. J Infect Dis 2009;200(November (Suppl. 1)):S16-27.

[21] Madhi SA, Cunliffe NA, Steele D, Witte D, Kirsten M, Louw C, et al. Effect of human rotavirus vaccine on severe diarrhea in African infants. $\mathrm{N}$ Engl J Med 2010;362(January (4)):289-98.

[22] Armah GE, Sow SO, Breiman RF, Dallas MJ, Tapia MD, Feikin DR, et al. Efficacy of pentavalent rotavirus vaccine against severe rotavirus gastroenteritis in infants in developing countries in sub-Saharan Africa: a randomised, double-blind, placebo-controlled trial. Lancet 2010;376(August (9741)):606-14.

[23] Zaman K, Dang DA, Victor JC, Shin S, Yunus M, Dallas MJ, et al. Efficacy of pentavalent rotavirus vaccine against severe rotavirus gastroenteritis in infants in developing countries in Asia: a randomised, double-blind, placebo-controlled trial. Lancet 2010;376(August (9741)):615-23.

[24] Clark A, Sanderson C. Timing of children's vaccinations in 45 low-income and middle-income countries: an analysis of survey data. Lancet 2009;373(May (9674)):1543-9.

[25] Rheingans RD, Constenla D, Antil L, Innis BL, Breuer T. Potential costeffectiveness of vaccination for rotavirus gastroenteritis in eight Latin American and Caribbean countries. Pan Am J Public Health 2007;21(April (4)):205-16.

[26] Murray C, Lopez A. The global burden of disease: a comprehensive assessment of mortality and disability from diseases, injuries and risk factors in 1990 and projected to 2020. Boston, MA: School of Public Health, Harvard University; 1996.

[27] Population Division of the Department of Economic and Social Affairs of the United Nations Secretariat. World Population Prospects: The 2006 Revision; 2007.

[28] Liddle JL, Burgess MA, Gilbert GL, Hanson RM, McIntyre PB, Bishop RF, et al. Rotavirus gastroenteritis: impact on young children, their families and the health care system. Med J Aust 1997;167(6):304-7.

[29] Baltussen R, Adam T, Tan Torres T, Hutubessy R, Acharya A, Evans D, et al. Generalized cost effectiveness analysis: a guide. Geneva: World Health Organization; 2002.

[30] Country-specific unit costs for health services. [Website] 2008 [cited 09.07.11]. Available from: http://www.who.int/choice/country/ country_specific/en/index.html.

[31] World Health Organization. Review of treatment cost protocol studies. Geneva: WHO Department of Vaccines and Biologicals; 2001 [December 11-12, 2000].

[32] Rheingans RD, Constenla D, Antil L, Innis BL, Breuer T. Economic and health burden of rotavirus gastroenteritis for the 2003 birth cohort in eight Latin American and Caribbean countries. Pan Am J Public Health 2007;21(April (4)):192-204.

[33] Bureau of Labor Statistics. Consumer price index, 2000-2002 [cited 03.05.04]. Available from: http://www.bls.gov/cpi/home.htm.

[34] World Development Indicators Online, 2004 [cited 03.05.04]. Available from: http://www.worldbank.org/data/wdi2004/.

[35] Wolfson LJ. WHO immunization coverage estimates and trajectories (WHO ICET): World Health Organization, Department of Immunization, Vaccines, and Biologicals; 2008.

[36] Tate JE, Burton AH, Boschi-Pinto C, Steele AD, Duque J, Parashar UD. 2008 estimate of worldwide rotavirus-associated mortality in children younger than 5 years before the introduction of universal rotavirus vaccination programmes: a systematic review and meta-analysis. Lancet Infect Dis 2012;12(2):136-41.

[37] Parashar UD, Hummelman EG, Bresee JS, Miller MA, Glass RI. Global illness and deaths caused by rotavirus disease in children. Emerg Infect Dis 2003;9(5):565-72.

[38] Conclusions and recommendations from the Immunization Strategic Advisory Group. Wkly Epidemiol Rec 2006;81(January (1)):2-11.

[39] John TJ. Antibody response of infants in tropics to five doses of oral polio vaccine. Br Med J 1976;1(April (6013)):812.

[40] Simanjuntak CH, Paleologo FP, Punjabi NH, Darmowigoto R, Soeprawoto, Totosudirjo $\mathrm{H}$, et al. Oral immunisation against typhoid fever in Indonesia with Ty21a vaccine. Lancet 1991;338(October (8774)):1055-9.
[41] Suharyono, Simanjuntak C, Witham N, Punjabi N, Heppner DG, Losonsky G et al. Safety and immunogenicity of single-dose live oral cholera vaccine CVD 103-HgR in 5-9-year-old Indonesian children. Lancet 1992;340(September (8821)):689-94.

[42] Developing countries make record demand for life-saving vaccines, 2011 [cited 12.08.11]. Available from: http://www.gavialliance.org/ library/news/press-releases/2011/developing-countries-make-recorddemand-for-life-saving-vaccines/.

[43] GAVI. Rotavirus vaccine support, 2011 [cited 01.11.11]. Available from: http://www.gavialliance.org/support/nvs/rotavirus/.

[44] GAVI. Vaccines against major childhood diseases to reach 37 more countries, 2011 [cited 01.11.11]. Available from: http://www.gavialliance.org/ library/news/press-releases/2011/vaccines-against-major-childhooddiseases-to-reach-37-more-countries/.

[45] PAHO Revolving Fund: vaccine and syringe prices 2010. Pan American Health Organization Immunization Newsletter; February 2010.

[46] GAVI. GAVI welcomes lower prices for life-saving vaccines 2011 [cited 19.06.11]. Available from: http://www.gavialliance.org/media centre/press_releases/vaccine_prices.php.

[47] WHO Department of Immunization VaB. WHO's role in supporting emerging vaccine manufacturers; potential impact on vaccine market dynamics and price: a closer look at rotavirus vaccines 2010 [cited 14.08.11]. Available from: http://www.who.int/immunization/sage/2_Summaries_Complementary_ Presentations_Agenda_Item.pdf.

[48] Rheingans RD, Atherly D, Anderson J. Distributional impact of rotavirus vaccination in 25 GAVI countries: estimating disparities in benefits and costeffectiveness. Vaccine 2012;30(Suppl. 1):A15-23.

[49] Anderson RM, May RM. Immunisation and herd immunity. Lancet 1990;335(March (8690)):641-5.

[50] Lambert SB, Faux CE, Hall L, Birrell FA, Peterson KV, Selvey CE, et al. Early evidence for direct and indirect effects of the infant rotavirus vaccine program in Queensland. Med J Aust 2009;191(August (3)):157-60.

[51] de Palma O, Cruz L, Ramos H, de Baires A, Villatoro N, Pastor D, et al. Effectiveness of rotavirus vaccination against childhood diarrhoea in El Salvador: case-control study. BMJ 2010;2010(January):340.

[52] World Health Organization. Some strategies to reduce risk. In: World Health Report 2002: reducing risk promoting healthy lives. Geneva: WHO; 2002. p 100-44.

[53] Rotavirus vaccines: an update. Wkly Epidemiol Rec 2009;84(December (50)):533-40.

[54] Patel MM, Clark AD, Glass RI, Greenberg H, Tate J, Santosham M, et al. Broadening the age restriction for initiating rotavirus vaccination in regions with high rotavirus mortality: benefits of mortality reduction versus risk of fatal intussusception. Vaccine 2009;27(May (22)):2916-22.

[55] Tate JB, Boschi-Pinto AH, Steele C, Agocs AD, Duque M, Parashar J. UD global mortality associated with rotavirus disease among children in 2008: findings based on a systematic review and meta-analysis. Lancet Infect Dis 2011.

[56] Fox-Rushby JA, Hanson K. Calculating and presenting disability adjusted life years (DALYs) in cost-effectiveness analysis. Health Policy Plan 2001;16(September (3)):326-31.

[57] Ruiz-Palacios GM, Perez-Schael I, Velazquez FR, Abate H, Breuer T, Clemens SC, et al. Safety and efficacy of an attenuated vaccine against severe rotavirus gastroenteritis. N Engl J Med 2006;354(January (1)):11-22.

[58] Vesikari T, Karvonen A, Puustinen L, Zeng SQ, Szakal ED, Delem A, et al. Efficacy of RIX4414 live attenuated human rotavirus vaccine in Finnish infants. Pediatr Infect Dis J 2004;23(October (10)):937-43.

[59] Vesikari T, Matson DO, Dennehy P, Van Damme P, Santosham M, Rodriguez $Z$, et al. Safety and efficacy of a pentavalent human-bovine (WC3) reassortant rotavirus vaccine. N Engl J Med 2006;354(January (1)):2333.

[60] The World Bank Data, GDP per capita (current US\$). 2009 [cited 26.06.11]. Available from: http://data.worldbank.org/indicator/NY.GDP.PCAP.CD. 